\title{
The Relationship between Job Demands and Employees' Counterproductive Work Behaviors: The Mediating Effect of Psychological Detachment and Job Anxiety
}

\author{
Yang Chen, Shuang $\mathrm{Li}^{\star}$, Qing Xia and Chao He \\ School of Management, China University of Mining and Technology, Xuzhou, China
}

This study aims to explore the relation between job demands and counterproductive work behaviors (CWBs). A cross-sectional sample of 439 coal miners completed a selfreport questionnaire that assessed their job demands, psychological detachment, job anxiety, and CWBs in a Chinese context. The conceptual model, based on the stressordetachment model, was examined using structural equation modeling. The results

Edited by:

Badri Bajaj,

Jaypee Institute of Information

Technology, India

Reviewed by: Arianna Costantini, University of Verona, Italy Catherine S. Daus,

Southern Illinois University Edwardsville, United States

*Correspondence: Shuang Li

liprofessorcumt@126.com

Specialty section: This article was submitted to Organizational Psychology, a section of the journal Frontiers in Psychology

Received: 16 July 2017 Accepted: 12 October 2017 Published: 30 October 2017

Citation:

Chen Y, Li S, Xia Q and He C (2017)

The Relationship between Job

Demands and Employees Counterproductive Work Behaviors: The Mediating Effect of Psychological

Detachment and Job Anxiety. Front. Psychol. 8:1890. doi: 10.3389/fpsyg.2017.01890 suggest that psychological detachment mediates not only the relation between job demands and job anxiety but also that between job demands and CWBs. Furthermore, the relation between job demands and CWBs is sequentially mediated by psychological detachment and job anxiety. Our findings validate the effectiveness of the stressordetachment model. Moreover, we demonstrate that the underlying mechanism of the relation between job demands and CWBs can be explained by psychological detachment and job anxiety.

Keywords: job demands, psychological detachment, job anxiety, counterproductive work behaviors, stressordetachment model

\section{INTRODUCTION}

China is the world's largest producer and consumer of coal (International Energy Agency, 2000), and using coal as a main source energy will continue for the foreseeable future (Yan et al., 2011; Xue and Ren, 2012). Consequently, the development of China's national economy is influenced by the operations of coal enterprises. It has been shown that the smooth running of coal enterprises depends mainly on the coal miners' job performance (Wei et al., 2015). However, coal enterprises have encountered an unavoidable problem in their day-to-day operations: coal miners' counterproductive work behaviors (CWBs) (Peters and Clingan, 1989; Cao and Yang, 2010; Li et al., 2013).

Counterproductive work behavior has been defined as any voluntary act that violates organizational norms and, thus, harms or is intended to harm an organization or its members (Robinson and Bennett, 1995; Spector and Fox, 2005a). Scholars use different names to describe these behaviors, such as organizational misbehavior (Vardi and Wiener, 1996), workplace aggression (Neuman and Baron, 2005), antisocial behavior (Robinson and O'Leary-Kelly, 1998), and workplace deviance (Robinson and Bennett, 1997). All of these behaviors are 
included in the concept of CWBs (Sulea et al., 2015), and these types of voluntary behaviors include such negative aspects as theft, sabotage, aggression, absenteeism, violence, insulting others, indifference, rudeness, and violating safety procedures (Spector, 2005; Hystad et al., 2014; Cohen, 2016). Considering the nature of these behaviors, CWBs can undoubtedly have significant negative effects on organizations and their members (Bowling and Eschleman, 2010; Rotundo and Spector, 2010). CWBs have been found to exist very widely in enterprises (Appelbaum et al., 2007; Penney et al., 2011), such as banks (Amazue et al., 2014; Nawawi et al., 2017) and hospitals (Grieco, 1987; Ahmed et al., 2013). The United States Chamber of Commerce reports that around three quarters of employees have committed theft at least once (Shulman, 2005). Moreover, CWBs negatively impact individuals, groups, and organizations (Alias et al., 2013). For example, unauthorized web surfing costs organizations an estimated $£ 300$ million per year in lost productivity (Taylor, 2007). Given these high costs, many researchers have devoted efforts to studying CWBs. The majority of previous CWB studies focused mainly on personality (O'Neill and Hastings, 2011), social culture (Zhang et al., 2015), and job stressors (Zhou et al., 2014). However, very few empirical studies have adopted the perspective of recovery.

Recovery is an effective way to avoid stress; it is usually defined as the process during which an individual's functioning returns to its prestressor level and in which strain is reduced (Kinnunen et al., 2011). Through recovery, an individual's resources are replenished (Meijman and Mulder, 1998; Trougakos and Hideg, 2009). However, if their recovery is incomplete, individuals must devote more effort to their work to ensure tasks are completed on time, which may, in turn, cause strain. If this situation continues, health problems and sickness absence will occur (Meijman and Mulder, 1998). As a main recovery strategy, psychological detachment could help to avoid further consuming employees' resources and provides opportunities for their replenishment (Germeys and De Gieter, 2016).

Accordingly, Sonnentag and Fritz (2015) has proposed the stressor-detachment model to reveal the mechanism between stressor and strain reactions and subsequent performance. In the original stressor-detachment model, the effect of job stressors on strain is moderated and/or mediated by psychological detachment, and strain can lead to changes in job performance (Sonnentag, 2011; Sonnentag and Fritz, 2015). Although numerous studies have been conducted based on this model, most explore the connections between occupational stressors, psychological detachment, and strain reaction, such as fatigue (Sonnentag, 2011), well-being (Fritz et al., 2010b) and sleep (Sonnentag et al., 2008; Pereira and Elfering, 2014). Far less research has considered the connections between stressors, psychological detachment, negative affect, and job performance. Previous studies emphasize the moderating effect of psychological detachment, and most suggest that this is not significant (Safstrom and Hartig, 2013; DeArmond et al., 2014). To date, few studies have examined the mediating effect of psychological detachment (Germeys and De Gieter, 2016).

To fill this gap, the present study examines the mediating effect of psychological detachment on the relation between job stressor (i.e., job demands) and negative affect (i.e., job anxiety). Moreover, we also test their influence on subsequent performance (i.e., CWBs).

\section{LITERATURE REVIEW AND HYPOTHESES}

\section{Job Demands and Employees' CWBs}

Job demands refer to factors of a job that require continuous physical and/or psychological effort or skills and consume certain physiological and/or psychological costs (Bakker and Demerouti, 2007). Three job demands have received particular focus in prior research: high workload (Bakker et al., 2004, 2010; Jourdain and Chênevert, 2007; Petitta and Vecchione, 2011; Schmidt and Diestel, 2013; van Doorn and Hülsheger, 2015), time pressure (Rijk et al., 1998; van der Doef et al., 2000), and work-family conflict (Bakker et al., 2004, 2008; Demerouti et al., 2004; Jourdain and Chênevert, 2007). All three influence employee performance. Focusing specifically on the work characteristics of coal miners, such as three shifts per day, hard manual work, and no vacations or weekends, many will perceive the workload to be high; as coal miners lose wages if they complete tasks after the prescribed deadline, they are likely to feel time pressure; furthermore, with their workplace located in a remote region, and no vacations or weekends, coal miners may have little opportunity to fulfill their family responsibilities, and so may perceive that work interferes with their family life. Thus, we focus specifically on workload, time pressure, and work-family conflict.

As mentioned earlier, as job demands increase, workers' physiological and/or psychological resources are increasingly drained. This will cause negative work outcomes if enough requisite resources of individuals are not available (Demerouti et al., 2001). Many empirical studies have confirmed the existence of this relationship: for example, Schaufeli et al.'s (2002) study suggests that job demands could cause job burnout. Ceschi et al. (2016) also found that job demands cause CWBs through emotional exhaustion. Under circumstances of high job demands, the constant consumption of employees' resources leaves them unable to cope with these demands. Consequently, task difficulty increases and work enthusiasm declines, increasing the likelihood of absenteeism and absence (Hakanen et al., 2006; Xanthopoulou et al., 2007). For example, Chen and Spector's (1992) study confirmed that job demands (e.g., role conflict, role ambiguity, workload, and interpersonal conflict) were positively related to employees' CWBs (e.g., workplace aggressive behaviors, theft, and waste behaviors).

The conservation of resources (COR) theory posits that all individuals tend to gain and maintain valuable resources. When such resources are threatened, lost, or insufficiently returned to cover the resources invested (Hobfoll, 1989), individuals may withdraw their efforts to conserve resources (Halbesleben and Bowler, 2007; Ng and Feldman, 2012; Kiazad et al., 2014). In line with this, as high job demands constantly consume employees' resources (Bakker and Demerouti, 2007), they will reduce efforts to restore loss or obtain new resources, which will cause CWBs, 
such as sabotage or absenteeism (Kanten and Ulker, 2013; Amazue et al., 2014). Therefore, we propose that:

H1: Job demands (workload, time pressure, and work-family conflict) are positively related to CWBs.

\section{Mediating Role of Job Anxiety}

Job anxiety is an emotional response to uncertainty, vague fear, insecurity, and worry as regards one or several constituents of a particular job (Srivastava, 1985; Lazarus, 1991). Research shows that job stressors are a barrier to achieving individual goals (Hacker, 2003), making the individual prone to anxiety (Skinner and Brewer, 2002). As a form of job stressor, job demands are likely to provoke fear of failing to achieve organizational goals, therefore leading to anxiety. This is because high job demands require employees to devote more efforts to sustain an expected performance level (Hakanen et al., 2006). Under high job demands (e.g., workload, time pressure and work-family conflict), employees' physical strength and energy are consumed (Demerouti et al., 2001), potentially causing them to feel that the job exceeds their capabilities (Hakanen et al., 2005), which could lead to low job control (Parker, 1998). Hence, as employees feel uncertain and worried over whether they can complete tasks and successfully achieve goals, anxiety eventually emerges. Accordingly, we hypothesize:

H2: Job demands (workload, time pressure, and work-family conflict) are positively related to job anxiety.

Previous research on CWBs has confirmed that job anxiety influences these behaviors. For example, based on a study of 288 patients with chronic mental disorders, Muschalla and Linden (2014) found that job anxiety causes employee absenteeism. Moreover, research suggests that individuals with high job anxiety always feel dissatisfaction with their job (Bücker et al., 2014), and employees may seek to reduce job dissatisfaction by engaging in CWBs (Greenidge et al., 2014; Zhang and Deng, 2016). In addition, job anxiety could lead to decreased conscientiousness (Bruce and Lynch, 2011), and low conscientiousness is a predictor of employees' CWBs, such as absenteeism and dishonesty (Salgado et al., 2013). Therefore, we hypothesize:

\section{H3: Job anxiety is positively related to employees' CWBs.}

The stressor-emotion model posits that emotions may mediate the relation between stressors and CWBs. When individuals are exposed to a job stressor, they may feel stress, which has the potential to induce a range of negative emotions. To reduce negative emotions, employees are more prone to engage in CWBs to counter job stressors (Spector and Fox, 2005b). In accordance with this view, job anxiety (a form of negative emotion) (Balducci et al., 2012) may mediate the relationship between job demands and CWBs. This is because job demands are the stressor (Bakker et al., 2004) which may hinder achievement of the individual goals (Hacker, 2003). Under the stress of job demands, employees fear about failure to achieve work goals, therefore leading to job anxiety (Skinner and Brewer, 2002), and employees may seek to reduce job anxiety by engaging in CWBs (Muschalla and Linden,
2014). Combining theoretical arguments with hypotheses $\mathrm{H} 1$ to $\mathrm{H} 3$, job anxiety may be assumed to play a mediator role in the relation between job demands and CWBs. Therefore, we hypothesize:

H4: Job anxiety mediates the relation between job demands and employees' CWBs.

\section{Psychological Detachment as a Mediator}

Psychological detachment refers to individuals not engaging in job-related activities and mentally disengaging themselves from job-related thoughts and worries during off-work time. In short, it is the experience of leaving one's work behind during non-work time (Sonnentag and Fritz, 2007). Numerous studies have demonstrated that the factors related to work, especially its stressors, have a great effect on psychological detachment (Sonnentag et al., 2010; Kinnunen et al., 2011). For example, Safstrom and Hartig (2013) provided evidence for the existence of this relationship. In their study, taking 173 university students who participated in challenging programs of advanced professional studies, high job demands were found to hinder psychological detachment. High job demands (e.g., workload and time pressure) lead to low psychological detachment. On the one hand, this may be explained by high workload and time pressure causing prolonged activation, which, in turn, inhibits mental disconnect from work-related issues (Brosschot et al., 2006). On the other hand, employees may need to continue working during off-job time and/or might anticipate in the evening that their workload will also be high the following day, which makes psychological detachment more difficult (Sonnentag, 2012). Thus, we propose that:

H5: Job demands are negatively related to psychological detachment.

Psychological detachment might affect employees' CWBs. This is because psychological detachment during off-work time could help employees to recover from job stressors and recover resources (e.g., energy and physical strength) (Fritz et al., 2010b). Moreover, according to COR theory, when an individual's resources are replenished, psychological strain is reduced and he/she is less likely to engage in CWBs (Penney et al., 2011). In addition, it is helpful for employees to show work engagement, when they get the resources are needed at work (Kühnel et al., 2009). And work engagement has been found to be negatively related to employees' CWBs (Ariani, 2013). Accordingly, we hypothesize:

H6: Psychological detachment is negatively related to employees' CWBs.

According to the stressor-detachment model, psychological detachment mediates the relation between job stressors and strains. Stressors can elicit strain reactions, which include physiological responses, psychological reactions, and negative behaviors (e.g., argument with a co-worker). If employees detach from work during off-work time, the effects of job stressors on employees are greatly diminished (Sonnentag and Fritz, 2015). Given that high job demands lead to strain reactions from 
employees, such as CWBs, if they are able to psychologically detach from the job outside work, the demands no longer consume their resources, which would help to reduce CWBs (de Jonge and Peeters, 2009). Combining theoretical arguments with hypotheses $\mathrm{H} 1, \mathrm{H} 5$, and $\mathrm{H} 6$, psychological detachment can be assumed to play a mediator role in the relation between job demands and CWBs. Therefore, we hypothesize:

H7: The relation between job demands and employees' CWBs is mediated by psychological detachment.

Some studies argue that psychological detachment is related to job anxiety (Moreno-Jiménez et al., 2012; Moreno-Jiménez and Herrer, 2013). This is because psychological detachment has been shown to reduce employees' worry (Sonnentag and Fritz, 2015), which will, in turn, reduce the possibility of anxiety (Srivastava, 1985). In addition, it is easier for employees who are psychologically detached from work to shift from a work role into a non-work role during downtime (Ashforth et al., 2000), thus avoiding the job anxiety caused by role conflict (Gomez, 2014). Flaxman et al. (2012) confirmed that psychological detachment has a negative effect on job anxiety, based on a study of 77 academic employees in the United Kingdom. In addition, while job demands drain an individual's resources (e.g., energy and physical strength), psychological detachment could remove the negative effects of job demands on the individual. Removing the mental influence of job demands from the individual can enable resources depleted during work to be rebuilt (Kühnel et al., 2009), which may improve job control and, consequently, decrease job anxiety (Battams et al., 2014). Combining theoretical arguments with hypotheses $\mathrm{H} 2$ and $\mathrm{H} 5$, we hypothesize:

H8: Psychological detachment is negatively related to job anxiety.

H9: Psychological detachment mediates the relation between job demands and job anxiety.

Based on the stressor-detachment model and previous research, we develop a multivariate model to examine our hypotheses, especially the proposed mediating effect of psychological detachment and job anxiety on the relation between job demands and CWBs. The conceptual model we propose in the present study is depicted in Figure 1.

\section{MATERIALS AND METHODS}

\section{Participants and Procedures Participants}

The study's participants are full-time coal miners from three large state-owned coal mines in northern China. The data were collected via paper-and-pencil questionnaires. In total, 540 questionnaires were issued and 487 were returned $(90.2 \%$ response rate). Questionnaires less than $50 \%$ completed and those that contained illegible responses were removed (48 responses). Following these exclusions, 439 valid questionnaires remained (81.3\% valid response rate).
Due to the nature and uniqueness of the industry, most coal company workers are men; thus, $90 \%$ of the valid respondents were men. The age groups were as follows: $12.3 \%$ aged under 25 , $45.1 \%$ aged $26-35,26.9 \%$ aged $36-45,15.3 \%$ aged $46-55$ years, and $0.5 \%$ aged 56 and above. Most of the participants have senior middle school education (33.1\%), followed by junior college (22.8\%), junior middle school (21.2\%), bachelor degree and above (19.6\%), and primary school and below (3.4\%). On job tenure, 9.6\% have worked for their organization for less than 1 year, $9.6 \%$ for $1-3$ years, $13.4 \%$ for $3-5$ years, $29 \%$ for $5-10$ years, and $38.5 \%$ for more than 10 years. The respondents' reported positions were as follows: general workers (82.1\%), first-line managers (14.6\%), middle managers $(2.7 \%)$, and senior managers $(0.7 \%)$. Most respondents were married $(87.7 \%)$, while $10.9 \%$ were unmarried $(10.9 \%)$ and $1.4 \%$ reported "other."

\section{Procedures}

The data were collected over approximately 1 month from May to June 2017. First, we contacted each company's HR manager to invite participation in our investigation; all of those we contacted were willing to allow their employees to participate. We then divided our research team into three groups, each of which was assigned to a different company. Assisted by the HR managers, 180 questionnaires were sent to workers at each of the three companies. Each questionnaire was accompanied by a cover letter explaining the purpose of the study, that participation was voluntary, and that participants' privacy would be strictly protected. Invitees were required to complete the paper-and-pencil questionnaire within $20 \mathrm{~min}$ in a designated meeting room during meeting time. All the questionnaires were collected in situ when the 20 min elapsed. To convey our appreciation, participants were offered the gift of a high-quality pen for completing the questionnaire. This study was part of a larger research project on coal miners' behaviors. Our study was approved by our university's ethics committee.

\section{Measures}

Each variable in the self-administered survey was measured using a multi-item scale, each of which was adopted from relevant prior research. As all our participants were Chinese, we followed the double-blind back-translation procedure (Schaffer and Riordan, 2003) to translate all items into Chinese. To avoid translation ambiguity, each item was translated by professional translators. The internal consistency of each scale was verified through Cronbach's alpha.

\section{Job Demands Workload}

This was assessed using the four-item scale of De Grood (2009), which was originally developed by Caplan et al. (1975). Participants' responses were measured on a 5-point Likert scale, ranging from strongly disagree (1) to strongly agree (5). Sample items of this scale include, "My workload is too heavy in my job" and "I have to work very quickly to get everything done in my job." The scale's Cronbach's alpha for this sample was 0.78 . 


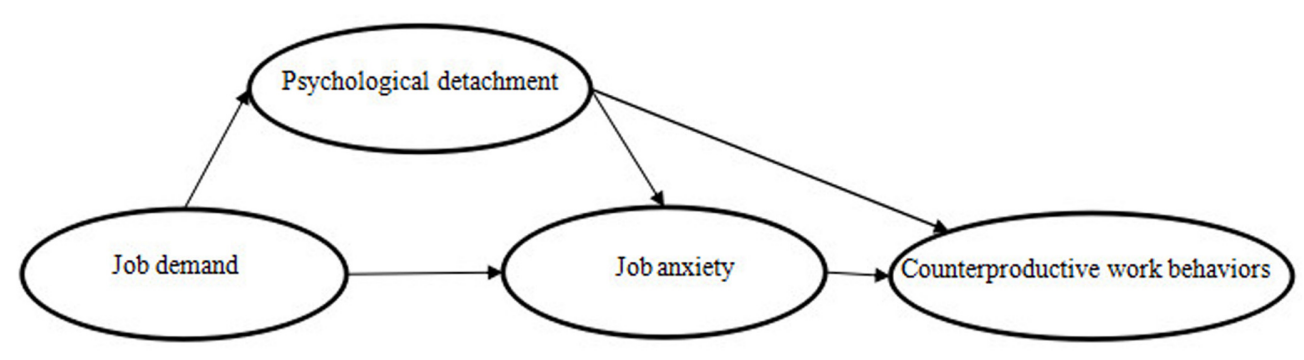

FIGURE 1 | Hypothetical model (based on the stressor-detachment model).

\section{Time pressure}

This was assessed using a five-item scale adopted from Aleksić et al. (2017). Responses were measured on a 5-point Likert scale, ranging from strongly disagree (1) to strongly agree (5). The sample items include: "When working, I have only a limited amount of time to finish my work" and "When working, I am in a hurry." The scale's Cronbach's alpha for this sample was 0.79 .

\section{Work-family conflict}

This was assessed using a five-item scale developed by Netemeyer et al. (1996), designed to measure the extent to which employees feel that work interferes with their family life. Given the evidence that work interferes with family life to a greater degree than family life interferes with work (Frone et al., 1992; Eagle et al., 1997; Swanson et al., 1998; Emslie et al., 2004). Thus, in this study, we have chosen to focus on work-to-family conflict (which we refer to as 'work-family conflict'). Responses were measured on a 5-point Likert scale, ranging from strongly disagree (1) to strongly agree (5). The sample items include: "The demands of my work interfere with my home and family life" and "The amount of time my job takes up makes it difficult for me to fulfill my family responsibilities." The scale's Cronbach's alpha for this sample is 0.86 .

\section{Psychological Detachment}

The four-item scale to measure psychological detachment was adopted from the work of Sonnentag and Fritz (2007). This scale refers to employees' views on their non-work time over the past few weeks. Every item was rated on a 5-point Likert scale, ranging from fully disagree (1) to fully agree (5). Sample items include: "I don't think about work at all during non-work time" and "I get a break from the demands of work during non-work time." Cronbach's alpha was 0.80 .

\section{Job Anxiety}

The eight-item job anxiety scale developed by McCarthy et al. (2016) was applied to assess participants' current job-related anxiety. Each item was measured on a 5-point Likert scale, ranging from absolutely disagree (1) to absolutely agree (5). Sample items include: "I am overwhelmed by thoughts of doing poorly at work" and "I often feel anxious that I will not be able to perform my job duties in the allotted time." Cronbach's alpha was 0.87 .

\section{Counterproductive Work Behaviors}

We assessed CWBs with a 19-item measure of quantitative CWBs developed by Robinson and Bennett (1995). Participants responded to each item on a 5 -point Likert scale $(1=$ Never, 5 = Everyday). The scale is a multidimensional construct including two portions: (a) 7 items for CWB aims to the individual members (CWB-I) $(\alpha=0.78)$, (b) 12 items for CWB aims to the organization (CWB-O) $(\alpha=0.75)$. Examples of the statements include: "Made fun of someone at work" and "Dragged out work in order to get overtime." Cronbach's alpha of the whole scale was 0.73 .

To rule out the potential confounding effects of demographic variables and some work-related background variables, we controlled for gender, age, education, job tenure, position, and marital status. First, gender was divided into two categories $(0=$ male; $1=$ female $)$. Second, to protect privacy, participants were divided into five age groups $(1=$ under $25 ; 2=26-35$ years old; $3=36-45 ; 4=46-55 ; 5=56$ and above). Third, education was divided into five categories $(1=$ primary school and below; $2=$ junior middle school; $3=$ senior middle school; $4=$ junior college; 5 = bachelor degree and above). Job tenure was also divided into five categories $(1=$ under 1 year; $2=1-3$ years; $3=3-5$ years; $4=5-10$ years; $5=$ over 10 years). Fourth, to avoid the potential effects of position, we treated it as control variable by dividing into four categories $(1=$ general worker; $2=$ firstline manager; $3=$ middle manager; $4=$ senior manager). Finally, marital status was divided into unmarried (1), married (2), and others (3).

\section{Data Analytic Strategy}

For data analysis, SPSS version 21.0 was used to analyze the internal consistency, descriptive statistics, and correlations among the variables. In conducting the two-step approach to test the mediating effects, as suggested by Anderson and Gerbing (1988), we utilized AMOS version 22.0. First, the measurement model was tested using confirmatory factor analysis (CFA) to assess the variables' discriminate validity (Cheung and Wong, 2011; Choi and Moon, 2017). The fit indices of the hypothesized factor model were compared with those of alternative factor models to confirm which better fit the data (Mathieu and Farr, 1991; Cheung and Wong, 2011). The second step, viable only after validation through the first step, was to use maximum likelihood structural equation modeling (SEM) to examine the structural relationships among the study variables. 
The following indices were used to study the adequacy of the estimated model: goodness-of-fit index (GFI), $\chi^{2} / \mathrm{df}$, normed fit index (NFI), root mean square error of approximation (RMSEA), and comparative fit index (CFI). An acceptable $\chi^{2} / \mathrm{df}$ is between 1 and 5 (Salisbury et al., 2002). The GFI, NFI, and CFI should each be over 0.90 (Salisbury et al., 2002). Finally, the RMSEA should be less than 0.08 (Byrne, 2006).

\section{RESULTS}

\section{Common Method Bias}

Common method bias (CMB) can inflate relationships when the data are collected from a single source (Podsakoff et al., 2003). To determine whether $\mathrm{CMB}$ is problematic in this study, the CFA marker technique was employed (Podsakoff et al., 2012). We built the CFA (5-factor) model by adding the CMB variable to the 4factor model. Compared with the 4 -factor model $\left(\chi^{2} / \mathrm{df}=4.29\right.$, $\mathrm{GFI}=0.98, \mathrm{NFI}=0.95, \mathrm{CFI}=0.96$, RMSEA $=0.068)$, the CFA (5-factor) model $\left(\chi^{2} / \mathrm{df}=7.20, \mathrm{GFI}=0.93\right.$, NFI $=0.86$, $\mathrm{CFI}=0.87$, RMSEA $=0.119)$ is no better. Further, the chi-square difference also did not reach the significant level $\left[\Delta \chi^{2}(9)=7.88\right.$, $p>0.05$ ]. Thus, $\mathrm{CMB}$ was negligible in our study (see Table 3 ).

\section{Description}

Before testing our hypotheses, we examined the intraclass correlation coefficient (ICC) (see Table 1). The result show that the data's reliability is good.

The means and standard deviations of and the correlations between each of the variables are presented in Table 2. Workload, time pressure, and work-family conflict are all positively related to employees' CWBs $(r=0.25, p<0.001 ; r=0.21, p<0.001$; $r=0.46, p<0.001)$ and job anxiety $(r=0.31, p<0.001$; $r=0.25, p<0.001 ; r=0.42, p<0.001)$. Workload, time pressure, and work-family conflict were all significantly and negatively correlated with psychological detachment $(r=-0.29, p<0.001$; $r=-0.31, p<0.001 ; r=-0.19, p<0.001)$. Thus H1, H2, and $\mathrm{H} 5$ were each preliminary supported. Psychological detachment was negatively associated with CWBs $(r=-0.21, p<0.001)$ and job anxiety $(r=-0.34, p<0.001)$, providing preliminary support for $\mathrm{H} 6$ and $\mathrm{H} 8$. Job anxiety was related positively to CWBs $(r=0.47, p<0.001)$, providing preliminary support for H3. As the correlations between the control variables and our

TABLE 1 | The intraclass correlation coefficient of the variables.

\begin{tabular}{lccc}
\hline Name & Estimate value & \multicolumn{2}{c}{$\mathbf{9 5 \%} \mathbf{C l}$} \\
\cline { 3 - 4 } & & Lower bounds & Upper bounds \\
\hline ICC1 & 0.852 & 0.829 & 0.872 \\
ICC2 & 0.793 & 0.758 & 0.824 \\
ICC3 & 0.844 & 0.820 & 0.866 \\
ICC4 & 0.900 & 0.886 & 0.914 \\
\hline
\end{tabular}

ICC1, the intraclass correlation coefficient of job demands; ICC2, the intraclass correlation coefficient of psychological detachment; ICC3, the intraclass correlation coefficient of job anxiety; ICC4, the intraclass correlation coefficient of CWB.

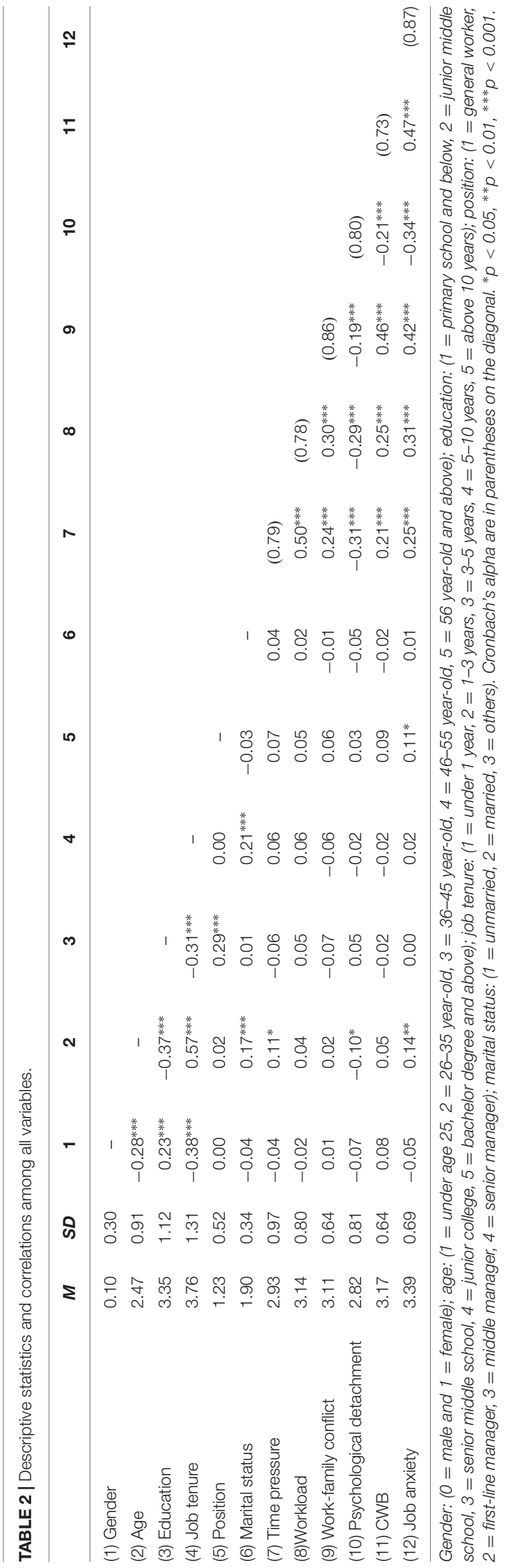


study variables were either weak or not significant, we do not further consider the effects of control variables in subsequent analysis.

\section{Measurement Model Testing}

We next performed CFA using AMOS 22.0. To increase the accuracy of parameter estimates, the method of item parceling should be adopted to represent variables' indicators (Rogers and Schmitt, 2004). Therefore, four latent factors (job demands, psychological detachment, job anxiety, and CWBs) and nine observed indicators were included in the study. When comparing with item-level data, the advantages of aggregate-level data (e.g., higher communality and lower random error) are obvious ( $\mathrm{Li}$ et al., 2017). The measurement model was tested by comparing the fit indices between the single-factor model (job demands, job anxiety, psychological detachment, and CWBs combined into one factor), 2-factor model (job demands, job anxiety, and

TABLE 3 | Comparison of measurement model.

\begin{tabular}{lccccccc}
\hline Structure & $\chi^{\mathbf{2}}$ & df & $\chi^{\mathbf{2}} / \mathbf{d f}$ & GFI & NFI & CFI & RMSEA \\
\hline 1- factor & 372.23 & 27 & 13.79 & 0.85 & 0.65 & 0.67 & 0.171 \\
2- factor & 213.23 & 26 & 8.20 & 0.90 & 0.80 & 0.82 & 0.128 \\
3- factor & 188.61 & 24 & 7.86 & 0.92 & 0.82 & 0.84 & 0.125 \\
4- factor & 94.29 & 21 & 4.29 & 0.98 & 0.95 & 0.96 & 0.068 \\
5- factor & 86.41 & 12 & 7.20 & 0.93 & 0.86 & 0.87 & 0.119
\end{tabular}

1-factor: JD (TP; WL; WC)+PD+JA+CWB; 2-factor: JD+JA+CWB; $P D$; 3-factor: JD, PD; JA+CWB; 4-factor: JD, PD, JA, CWB; 5-factor: JD, PD, JA, CWB, CMB. $J D$, job demands; TP, time pressure; WL, workload; WC, work-family conflict; $P D$, psychological detachment; JA, job anxiety; CWB, counterproductive work behavior; CMB, common method bias.
CWBs on the same factor; psychological detachment on the other), 3-factor model (job demands and job anxiety on the same factor; psychological detachment and CWBs as separate factors), and 4-factor model (job demands, job anxiety, psychological detachment, and CWBs as separate factors). The results suggested that the 4-factor model $\left(\chi^{2} / \mathrm{df}=4.29\right.$, GFI $=0.98$, NFI $=0.95$, CFI $=0.96$, RMSEA $=0.068$ ) provided a better fit than the other models (see Table 3). In organizational behavior studies, the method explained above has been widely used in prior research (Mathieu and Farr, 1991; Cheung and Wong, 2011).

\section{Structure Model Testing}

We use SEM to examine the mediating effects of psychological detachment and job anxiety and to assess our proposed model. In the original stressor-detachment model, there is no direct effect from psychological detachment to subsequent performance. Thus, we built an alternative Model 1 (see Figure 2), in which the direct path from psychological detachment to CWBs was deleted from our Hypothetical model (based on the stressordetachment model) (Figure 1). The results showed that Model $1\left(\chi^{2} / \mathrm{df}=7.47, \mathrm{GFI}=0.92, \mathrm{NFI}=0.84, \mathrm{CFI}=0.86\right.$, RMSEA $=0.122)$ did not fit the data well. Compared with the Hypothetical model $\left(\chi^{2} / \mathrm{df}=7.72\right.$, GFI $=0.92$, NFI $=0.94$, $\mathrm{CFI}=0.86$, RMSEA $=0.124)$, the chi-square difference did not reach the significant level $\left[\Delta \chi^{2}(1)=2.03, p>0.05\right]$, suggesting that Model 1 did not fit the data better than the Hypothetical model (see Table 4).

We then built Model 2 (see Figure 3), in which a direct path from job demands to CWBs was added to Model 1. The results demonstrated that Model $2\left(\chi^{2} / \mathrm{df}=7.28\right.$, $\mathrm{GFI}=0.92$, NFI $=0.85, \mathrm{CFI}=0.87$, RMSEA $=0.120)$ also

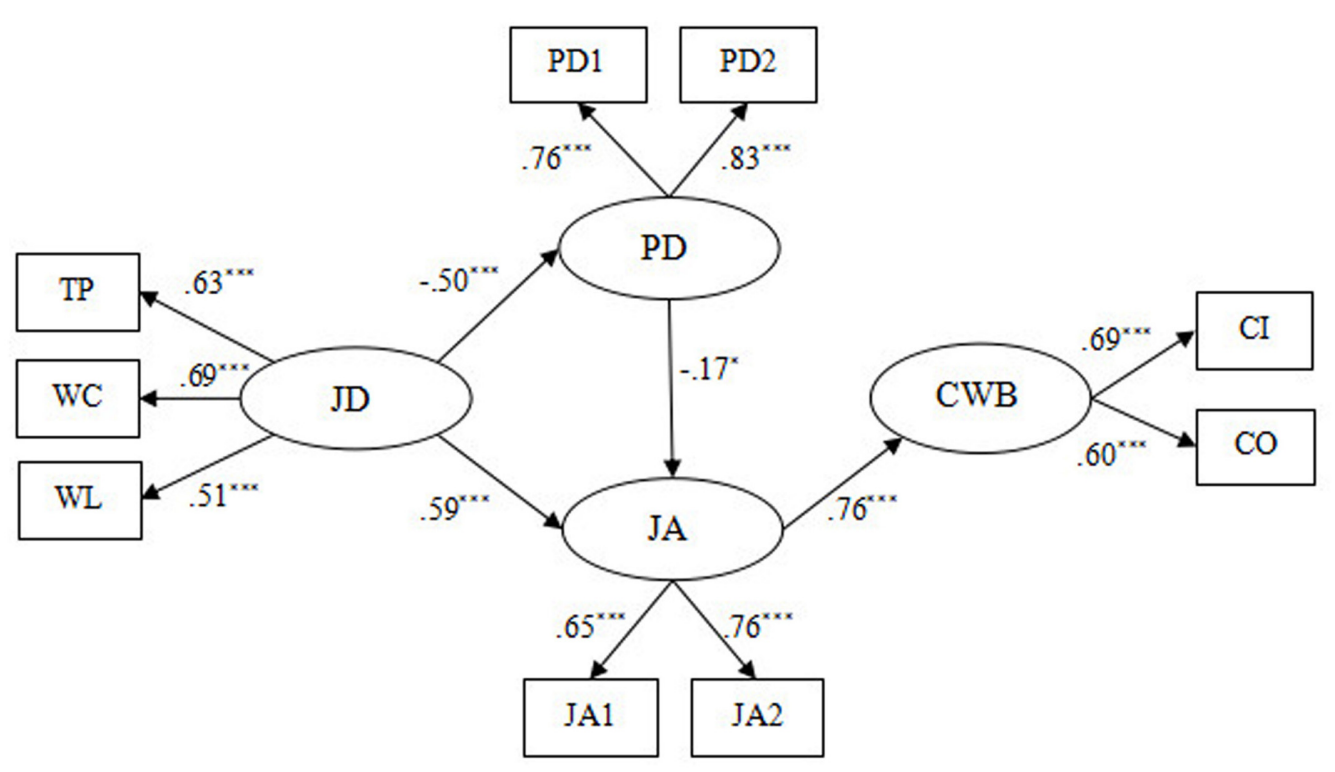

FIGURE 2 | The original stressor-detachment model (Model 1). JD, job demands; TP, time pressure; WL, workload; WC, work-family conflict; PD, psychological detachment; JA, job anxiety; CWB, counterproductive work behavior; Cl, CWB-I; CO, CWB-O; PD1 and PD2 aggregate of two items from Psychological Detachment Questionnaire, respectively; JA1 and JA2 aggregate of four items from Job Anxiety Questionnaire, respectively * $p<0.05, * * p<0.01, * * * p<0.001$. 
TABLE 4 | Comparison of the structural models.

\begin{tabular}{lccccccc}
\hline Model & $\chi^{2}$ & $\boldsymbol{d f}$ & $\chi^{\mathbf{2} / \mathbf{d f}}$ & GFI & NFI & CFI & RMSEA \\
\hline $\begin{array}{l}\text { Hypothetical } \\
\text { model }\end{array}$ & 169.82 & 22 & 7.72 & 0.92 & 0.94 & 0.86 & 0.124 \\
M1 & 171.85 & 23 & 7.47 & 0.92 & 0.84 & 0.86 & 0.122 \\
M2 & 160.12 & 22 & 7.28 & 0.92 & 0.85 & 0.87 & 0.120 \\
M3 & 83.16 & 21 & 3.96 & 0.97 & 0.94 & 0.95 & 0.073 \\
M4 & 150.90 & 21 & 7.19 & 0.93 & 0.86 & 0.87 & 0.119 \\
\hline
\end{tabular}

has unsatisfactory data fitting (see Table 4). Compared with Model 1 , the chi-square difference $\left[\Delta \chi^{2}(1)=11.73, p<0.05\right]$ reached a significant level, meaning that Model 2 is superior to Model 1.

To find the most satisfactory model, we then developed another alternative model (Model 3), in which a path from psychological detachment to CWBs was added to Model 2 (see Figure 4). The results demonstrated that Model 3 $\left(\chi^{2} / \mathrm{df}=3.96\right.$, GFI $=0.97, \mathrm{NFI}=0.94, \mathrm{CFI}=0.95$, RMSEA $=0.073)$ fitted the data well. Moreover, the factor loading of each indicator was between 0.53 and 0.80 , and all reached the significant level $(p<0.001)$ (see Figure 4). Hence, all of the indicators are suitable to represent their latent constructs. Through comparison of the chi-square change between Model 3 and the Hypothetical model $\left[\Delta \chi^{2}(1)=\right.$ 86.66, $p<0.001]$, Model 3 and Model $1\left[\Delta \chi^{2}(2)=88.69\right.$, $p<0.001]$, and Model 3 and Model $2\left[\Delta \chi^{2}(1)=76.96\right.$, $p<0.001]$, the significant level was reached, revealing that Model 3 significantly improves model fit and is superior to all of the alternative models (see Table 4). Thus, Model 3 was selected as our study's structural model (see Figure 4).
To determine the casual relationships between our study variables, we also test the reverse model (Model 4) (see Figure 5). The results show that the path coefficient from CWBs to job anxiety $(\beta=0.66, p<0.001)$ is significant. However, the fit indices of the reverse model are unsatisfactory (see Table 4). Therefore, the reverse model is not acceptable.

Furthermore, the bootstrapping method was used to test the mediation effects in Model 3. Bootstrapping is the ideal way to test indirect effects as it does not impose distributional assumptions (Zhang et al., 2015). The most accurate estimation of indirect effects can be obtained by bootstrap sampling. If zero is not included in the $95 \%$ confidence interval, then indirect effects are significant. The results showed that our hypotheses are all verified (see Tables 5, 6 and Figure 4). First, the total effect from job demands to CWBs was significant $(\beta=0.74, p<0.001)$, supporting $\mathrm{H} 1$. Second, the total effect from job demands to job anxiety was also significant $(\beta=0.67, p<0.01)$, supporting $\mathrm{H} 2$. Third, the direct effect from job anxiety to CWBs was significant ( $\beta=0.36, p<0.001)$, supporting H3. Fourth, the indirect effect of job demands on CWBs through job anxiety was significant $(\beta=0.21, p<0.05)$, supporting H4. Fifth, the direct effect from job demands to psychological detachment was significant $(\beta=-0.51, p<0.001)$, supporting H5. Sixth, the direct effect from psychological detachment to CWBs reached the significant level $(\beta=-0.25, p<0.01)$, supporting H6. Seventh, the indirect effect of job demands on CWB via psychological detachment was significant $(\beta=0.13, p<0.05)$, supporting H7. Eighth, the path coefficient between psychological detachment and job anxiety was significant $(\beta=-0.18, p<0.05)$, supporting $\mathrm{H} 8$. Ninth, job demands affected job anxiety through psychological detachment ( $\beta=0.09, p<0.05$ ), supporting H9. Finally, we also demonstrated that the relation between job demands and CWBs

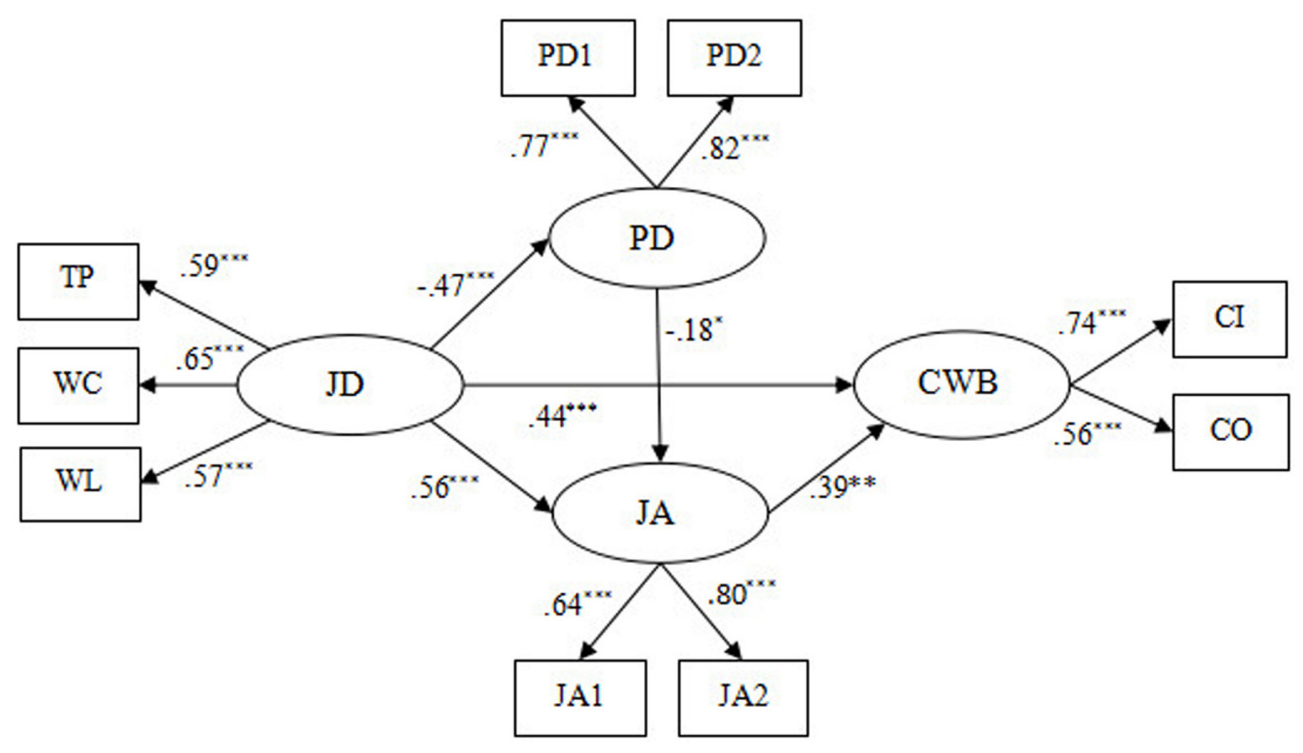

FIGURE 3 | The alternative model bases on the Model 1 (Model 2). JD, job demands; TP, time pressure; WL, workload; WC, work-family conflict; PD, psychological detachment; JA, job anxiety; CWB, counterproductive work behavior; Cl, CWB-I; CO, CWB-O; PD1 and PD2 aggregate of two items from Psychological Detachment Questionnaire, respectively; JA1 and JA2 aggregate of four items from Job Anxiety Questionnaire, respectively ${ }^{*} p<0.05$, ${ }^{* *} p<0.01,{ }^{* * *} p<0.001$. 


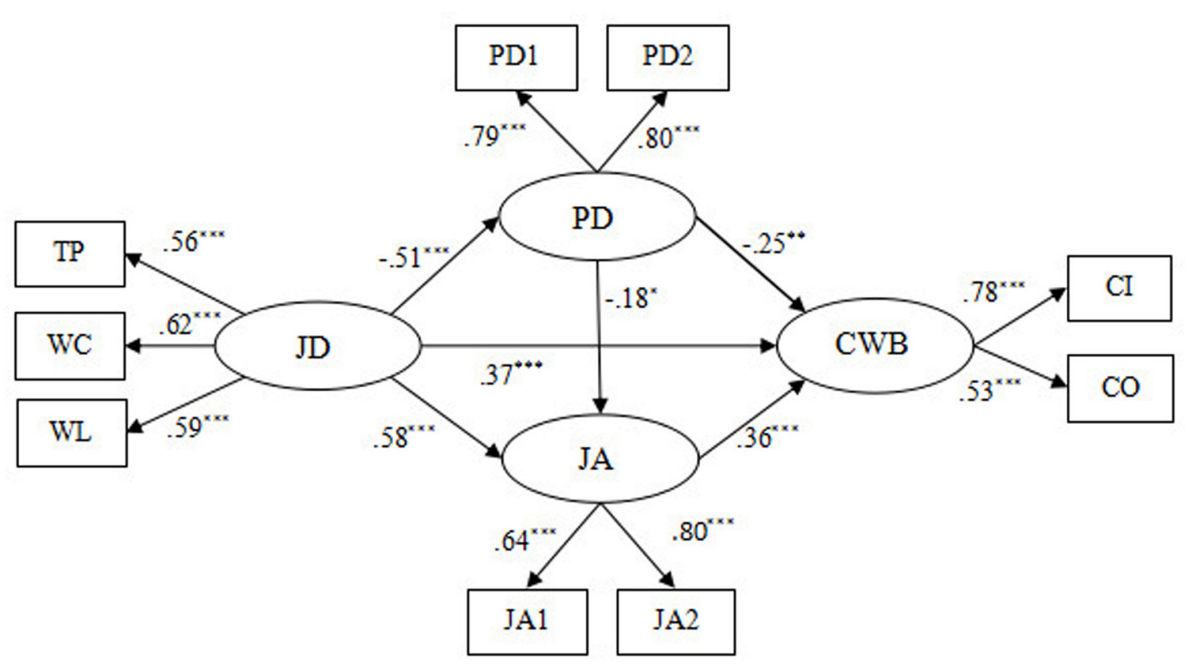

FIGURE 4 | The ultimate mediation model (Model 3). $N=439$. JD, job demands; TP, time pressure; WL, workload; WC, work-family conflict; PD, psychological detachment; JA, job anxiety; CWB, counterproductive work behavior; Cl, CWB-I; CO, CWB-O; PD1 and PD2 aggregate of two items from Psychological Detachment Questionnaire, respectively; JA1 and JA2 aggregate of four items from Job Anxiety Questionnaire, respectively * $p<0.05$, ${ }^{* *} p<0.01,{ }^{* * *} p<0.001$.

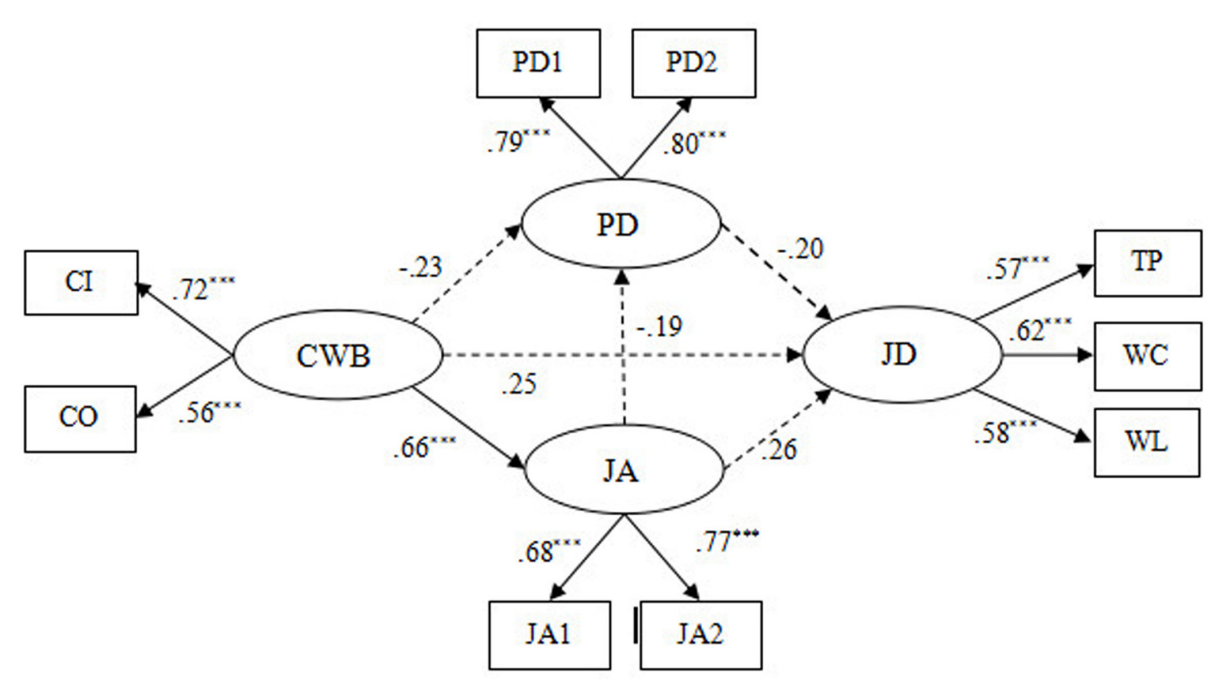

FIGURE 5| The reversed model (Model 4). JD, job demands; TP, time pressure; WL, workload; WC, work-family conflict; PD, psychological detachment; JA, job anxiety; CWB, counterproductive work behavior; Cl, CWB-I; CO, CWB-O; PD1 and PD2 aggregate of two items from Psychological Detachment Questionnaire, respectively; JA1 and JA2 aggregate of four items from Job Anxiety Questionnaire, respectively $*^{*} p<0.05,{ }^{* *} p<0.01,{ }^{* * *} p<0.001$.

was sequentially mediated by psychological detachment and job anxiety $(\beta=0.03, p<0.05)$.

\section{DISCUSSION}

Based on the stressor-detachment model, we confirmed that psychological detachment and job anxiety partially and sequentially mediate the relation between job demands and CWBs. Further, psychological detachment mediates the relation between job demands and job anxiety. Compared with the original stressor-detachment model, two additional path coefficients are significant (i.e., job demands to CWBs and psychological detachment to CWBs) in our model. This might be explained by CWBs working as both performance and strain reactors (Fida et al., 2015). Our research thereby makes several contributions to the stressor-detachment model and CWB literature.

\section{Theoretical Implications}

Our research has some theoretical implications. Primarily, this study extends the stressor-detachment model's application by demonstrating that psychological detachment mediates job demands' respective relations with job anxiety and CWBs. 
TABLE 5 | The results of the study.

\begin{tabular}{lcc}
\hline Hypothesis & Estimate effect & $\begin{array}{c}\text { Get supported } \\
\text { or not }\end{array}$ \\
\hline H1 & $0.74^{* * *}$ & Yes \\
H2 & $0.67^{* * *}$ & Yes \\
H3 & $0.36^{* * *}$ & Yes \\
H4 & $0.21^{*}$ & Yes \\
H5 & $-0.51^{* * *}$ & Yes \\
H6 & $-0.25^{* *}$ & Yes \\
H7 & $0.13^{*}$ & Yes \\
H8 & $-0.18^{*}$ & Yes \\
H9 & $0.09^{*}$ & Yes \\
\hline
\end{tabular}

${ }^{*} p<0.05,{ }^{* *} p<0.01,{ }^{*} p<0.001$.

TABLE 6 | Direct and indirect effects and 95\% confidence intervals in final model 3.

\begin{tabular}{|c|c|c|c|}
\hline \multirow{2}{*}{$\begin{array}{l}\text { Model } \\
\text { pathways }\end{array}$} & \multirow{2}{*}{$\begin{array}{c}\text { Estimated } \\
\text { effect }\end{array}$} & \multicolumn{2}{|c|}{$95 \% \mathrm{Cl}$} \\
\hline & & Lower bounds & Upper bounds \\
\hline
\end{tabular}

\begin{tabular}{lccr}
\hline Total effects & & \\
$\mathrm{JD} \rightarrow \mathrm{CWB}$ & $0.74^{* * *}$ & 0.568 & 0.904 \\
$\mathrm{JD} \rightarrow \mathrm{JA}$ & $0.67^{* *}$ & 0.488 & 0.826 \\
Direct effects & & & \\
$\mathrm{JD} \rightarrow \mathrm{PD}$ & $-0.51^{* * *}$ & -0.644 & -0.385 \\
$\mathrm{JD} \rightarrow \mathrm{CWB}$ & $0.37^{* * *}$ & 0.211 & 0.529 \\
$\mathrm{JD} \rightarrow \mathrm{JA}$ & $0.58^{* * *}$ & 0.368 & 0.785 \\
$\mathrm{PD} \rightarrow \mathrm{JA}$ & $-0.18^{*}$ & -0.337 & -0.022 \\
$\mathrm{PD} \rightarrow \mathrm{CWB}$ & $-0.25^{* *}$ & -0.422 & -0.072 \\
$\mathrm{JA} \rightarrow \mathrm{CWB}$ & $0.36^{* * *}$ & 0.054 & 0.666 \\
$\mathrm{Indirect}$ effects & & & 0.228 \\
$\mathrm{JD} \rightarrow \mathrm{PD} \rightarrow \mathrm{CWB}$ & $0.13^{*}$ & 0.030 & 0.160 \\
$\mathrm{JD} \rightarrow \mathrm{PD} \rightarrow \mathrm{JA}$ & $0.09^{*}$ & 0.021 & 0.038 \\
$\mathrm{JD} \rightarrow \mathrm{PD} \rightarrow \mathrm{JA} \rightarrow \mathrm{CWB}$ & $0.03^{*}$ & 0.022 & 0.389 \\
$\mathrm{JD} \rightarrow \mathrm{JA} \rightarrow \mathrm{CWB}$ & $0.21^{*}$ & 0.029 &
\end{tabular}

$J D$, job demands; PD, psychological detachment; JA, job anxiety; CWB, counterproductive work behavior. ${ }^{*} p<0.05,{ }^{* *} p<0.01,{ }^{*} p<0.001$.

Previous research focused mostly on detachment's moderating effect, with the mediating effect largely neglected (Sonnentag, 2011; Germeys and De Gieter, 2016). Thus, our study helps deepen understanding of the stressor-detachment model, and responds to Sonnentag's (2011) call to test the mediating effect of psychological detachment. The present study also added subsequent performance (i.e., CWBs) to the stressor-detachment model. The study moved beyond the limitations of prior research, which has mainly considered the relationships among stressors, psychological detachment, and strain (Safstrom and Hartig, 2013; Pereira and Elfering, 2014). Through empirical study, we found that job demands (a form of stressor) and job anxiety (a form of strain) have positive effects on CWBs (a form of performance), while psychological detachment has a negative effect on CWBs. These results are similar to those of DeArmond et al. (2014), and are also broadly in line with the stressordetachment model.
Second, our study extended the existing research on CWBs. Previous research has explained the formation mechanism of CWBs based mainly on the stressor-emotion model: the stressor elicits negative feelings and employees are prone to engage in CWB under their influence (Spector and Fox, 2005a). Though some research has examined the relationships among job demands, job-related affect (e.g., job anxiety), and CWBs (Spector and Fox, 2002; Balducci et al., 2011), few studies have examined the relation between psychological detachment and CWBs. This study reveals that CWBs can be explained by job demands and its relationship with psychological detachment and job anxiety. Thus, we proposed a new perspective to explain the formation mechanism of CWBs by introducing it into the stressordetachment model, thereby opening a new avenue for further research.

Third, we tested the role of job anxiety in the stressordetachment model. There is only limited research in which job anxiety, as a specific strain reaction, is incorporated in the stressor-detachment model. Through the literature review, we identified that earlier research tends to take fatigue as a strain reaction, but few consider job anxiety. The current study's results suggest that job demands and psychological detachment act as antecedent variables and CWBs as an outcome variable of job anxiety. Our study shifts from the previous studies' focus on personality traits (antecedent variables) (Gramstad et al., 2013; Starrenburg et al., 2013) and turnover intention (outcome variable) (Jensen et al., 2013; Vanderpool and Way, 2013; Husain et al., 2016). Thus, this study enriches understanding of the antecedent and outcome variables of job anxiety and contributes to existing knowledge about job anxiety by incorporating it as a key part of the stressor-detachment model.

\section{Practical Implications}

Our results also have several important practical implications. First, they confirm that job demands are positively related to job anxiety and CWBs, and negatively correlated with psychological detachment. These relationships should be considered by organizations in seeking to reduce job demands. For instance, job design and performance assessment should be based on the practical working capability of employees, and each should be allocated reasonable tasks. Thereby, staff could finish work on time and avoid continuing to work in offjob time. If the job demands cannot be reduced, organizations could create more opportunities for employees to attend training, for example, in setting priorities, time-management skills, and job skills, to help them to work more efficiently (Sonnentag et al., 2014) and avoid perceiving a high workload and time pressure. According to Rothbard et al. (2005), managing the boundaries between work and family depend on each employee's preference: an employee that wishes to integrate the two may set blurring role boundaries, while one who prefers to segment may set clear role boundaries. Therefore, to diminish work-family conflict, employees must be permitted to set boundaries between work and family in accordance with their own preference. At the same time, a more 
segmenting policy such as flextime should be implemented as this would not be detrimental to integrators and may marginally help segmentors (Rothbard et al., 2005).

Given that psychological detachment influences job anxiety and CWBs, employees should pursue leisure activities during off-job time (Sonnentag, 2012), such as exercising or developing new interests (Fritz et al., 2010a). Moreover, before starting work each day, it is helpful for employees to create a list (in order of priority) of work tasks that need to be completed that day (Fritz et al., 2010b): workers can, thereby, complete tasks through a planned approach, avoiding the need to engage in workrelated thoughts or activities during off-work time. In addition, debiasing trainings are the useful strategies to help employees to set priority (Ceschi et al., 2017). Further, both mangers and co-workers should not be available for and should avoid work-related communication with employees during off-work time.

Finally, to avoid negative effects from job anxiety, organizations should select and train employees carefully. For example, the 16 Personality Factor Questionnaire should be used to assess the personality characteristic of anxiety when recruiting (Chakravarthy and Chandramohan, 2015). In addition, organizations can seek to eliminate employees' worries or fear of failing to achieve organizational goals by setting realistic objectives for employees. Organizations could also provide training courses to teach employees' practical skills to cope with job anxiety, or create more opportunities for employees to receive psychological counseling and consultation.

\section{Limitations and Future Research}

Our study has several limitations that should be overcome in future research. Primarily, our study employed a crosssectional design. Therefore, it would be premature to draw exact conclusions about causality. Although some studies have validated the causal linkage between job anxiety and CWBs (Salami, 2010; Muschalla and Linden, 2014), alternative explanations are difficult to rule out. For instance, in our research, we assumed that employees with high job anxiety tend to engage in CWBs. Another possibility is that employees are punished for engaging in CWBs, which increases their job anxiety. For example, if an employee breaks the organization's rules, they may be punished, for example, through a pay deduction. Thereafter, they may worry about another pay deduction if they break the rules again, hence increasing their job anxiety. This may explain why the path coefficient

\section{REFERENCES}

Ahmed, W., Kiyani, A. A., and Hashmi, S. H. (2013). The study on organizational cynicism, organizational injustice \& breach of psychological contract as the determinants of deviant work behavior. Actual Probl. Econ. 2, 145-154. doi: 10.2147/AMEP.S88953

Aleksić, D., Mihelić, K. K., Ćerne, M., and Škerlavaj, M. (2017). Interactive effects of perceived time pressure, satisfaction with work-family balance (SWFB), and leader-member exchange (LMX) on creativity. Pers. Rev. 46, 662-679. doi: 10.1108/PR-04-2015-0085 between CWBs and job demands was significant $(\beta=0.66$, $p<0.001)$ in the reverse model. Thus, to confirm causal links, longitudinal and experimental studies should be employed in future research.

Second, the research data were collected through a selfreport form and all variables were assessed based on employees' perceptions, which may lead to CMB (Proenca et al., 2017). We took some measures to control the effect of CMB during questionnaire design and data analysis. However, Spector (2006) suggested that CMB may be not a serious issue in practice (Prottas et al., 2017). Further, the CFA marker technique demonstrated that $\mathrm{CMB}$ was not serious. Nonetheless, $\mathrm{CMB}$ is a potential limitation. Therefore, some other measurement methods, such as coworker assessment, leader assessment, depth interview, and behavioral observation should be employed in future research.

Third, as our data were only collected from three large, stateowned coal mines in northern China, the generalizability of our findings to other organizations is questionable. There are huge differences in the job characteristics and environment between coal mines and other industries (Qing-gui et al., 2012). Thus, to enhance the universality of the current conclusions future research should test our model in more diverse industries.

\section{ETHICS STATEMENT}

This study was carried out in accordance with the recommendations of ethics committee of China University of Mining and Technology with written informed consent from all subjects. All subjects gave written informed consent in accordance with the Declaration of Helsinki. The protocol was approved by the ethics committee of China University of Mining and Technology.

\section{AUTHOR CONTRIBUTIONS}

YC designed and drafted the work. SL collected the data. QX revised the manuscript. $\mathrm{CH}$ analyzed data for the study.

\section{FUNDING}

This study was supported by the National Natural Science Foundation of China (71573256), and the National Key Research and Development Plan of China (2017YFC0804408).

Alias, M., Samah, B. A., Rasdi, R. M., and Ismail, M. (2013). Predictors of workplace deviant behaviour: HRD agenda for Malaysian support personnel. Eur. J. Train. Dev. 37, 161-182. doi: 10.1108/030905913113 01671

Amazue, L. O., Onyishi, I. E., and Amazue, L. E. (2014). Surface acting and distress tolerance as predictors of workplace deviance among Nigerian commercial bank workers. Afr. J. Bus. Manage. 8, 582-587. doi: 10.5897/AJBM2014.7431

Anderson, J. C., and Gerbing, D. W. (1988). Structural equation modeling in practice: a review and recommended two-step approach. Psychol. Bull. 103, 411-423. doi: 10.1037/0033-2909.103.3.411 
Appelbaum, S. H., Iaconi, G. D., and Matousek, A. (2007). Positive and negative deviant workplace behaviors: causes, impacts, and solutions. Corp. Gov. 7, 586-598. doi: 10.1108/14720700710827176

Ariani, D. W. (2013). The relationship between employee engagement, organizational citizenship behavior, and counterproductive work behavior. Int. J. Bus. Adm. 4, 46-56. doi: 10.5430/ijba.v4n2p46

Ashforth, B. E., Kreiner, G. E., and Fugate, M. (2000). All in a day's work: boundaries and micro role transitions. Acad. Manage. Rev. 25, 472-491. doi: 10.5465/AMR.2000.3363315

Bakker, A. B., and Demerouti, E. (2007). The job demands-resources model: state of the art. J. Manag. Psychol. 22, 309-328. doi: 10.1108/02683940710733115

Bakker, A. B., Demerouti, E., and Verbeke, W. (2004). Using the job demandsresources model to predict burnout and performance. Hum. Resour. Manage. 43, 83-104. doi: 10.1002/hrm.20004

Bakker, A. B., Van Emmerik, H., and Van Riet, P. (2008). How job demands, resources, and burnout predict objective performance: a constructive replication. Anxiety Stress Coping 21, 309-324. doi: $10.1080 / 10615800801958637$

Bakker, A. B., Van Veldhoven, M., and Xanthopoulou, D. (2010). Beyond the demand-control model. J. Pers. Psychol. 9, 1-16. doi: 10.1027/1866-5888/ a000006

Balducci, C., Cecchin, M., Fraccaroli, F., and Schaufeli, W. B. (2012). Exploring the relationship between workaholism and workplace aggressive behaviour: the role of job-related emotion. Pers. Individ. Dif. 53, 629-634. doi: 10.1016/j.paid. 2012.05.004

Balducci, C., Schaufeli, W. B., and Fraccaroli, F. (2011). The job demandsresources model and counterproductive work behaviour: the role of jobrelated affect. Eur. J. Work Organ. Psychol. 20, 467-496. doi: 10.1080/ 13594321003669061

Battams, S., Roche, A. M., Fischer, J. A., Lee, N. K., Cameron, J., and Kostadinov, V. (2014). Workplace risk factors for anxiety and depression in male-dominated industries: a systematic review. Health Psychol. Behav. Med. 2, 983-1008. doi: $10.1080 / 21642850.2014 .954579$

Bowling, N. A., and Eschleman, K. J. (2010). Employee personality as a moderator of the relationships between work stressors and counterproductive work behavior. J. Occup. Health Psychol. 15, 91-103. doi: 10.1037/a0017326

Brosschot, J. F., Gerin, W., and Thayer, J. F. (2006). The perseverative cognition hypothesis: a review of worry, prolonged stress-related physiological activation, and health. J. Psychosom. Res. 60, 113-124. doi: 10.1016/j.jpsychores.2005. 06.074

Bruce, J. M., and Lynch, S. G. (2011). Personality traits in multiple sclerosis: association with mood and anxiety disorders. J. Psychosom. Res. 70, 479-485. doi: 10.1016/j.jpsychores.2010.12.010

Bücker, J. J., Furrer, O., Poutsma, E., and Buyens, D. (2014). The impact of cultural intelligence on communication effectiveness, job satisfaction and anxiety for Chinese host country managers working for foreign multinationals. Int. J. Hum. Resour. Manage. 25, 2068-2087. doi: 10.1080/09585192.2013.870293

Byrne, B. M. (2006). Structural Equation Modeling with EQS: Basic Concepts, Applications, and Programming. New York, NY: Routledge.

Cao, Q., and Yang, X. (2010). Study on coalmine safety behavior control system model and its manager behavior choice. J. Serv. Sci. Manage. 3, 165-172. doi: 10.4236/jssm.2010.31021

Caplan, R. D., Cobb, S., and French, J. R. (1975). Relationships of cessation of smoking with job stress, personality, and social support. J. Appl. Psychol. 60, 211-219. doi: $10.1037 / \mathrm{h} 0076471$

Ceschi, A., Costantini, A., Phillips, S. D., and Sartori, R. (2017). The career decision- making competence: a new construct for the career realm. Eur. J. Train. Dev. 41, 8-27.doi: 10.1108/EJTD-07-2016-0047

Ceschi, A., Sartori, R., Dickert, S., and Costantini, A. (2016). Grit or honestyhumility? New insights into the moderating role of personality between the health impairment process and counterproductive work behavior. Front. Psychol. 7:1799. doi: 10.3389/fpsyg.2016.01799

Chakravarthy, V., and Chandramohan, V. (2015). Effectiveness of cognitive behaviour therapy in the management of anxiety among school students. Int. J. Indian Psychol. 2, 109-115.

Chen, P. Y., and Spector, P. E. (1992). Relationships of work stressors with aggression, withdrawal, theft and substance use: an exploratory study. J. Occup. Organ. Psychol. 65, 177-184. doi: 10.1111/j.2044-8325.1992.tb00495.x
Cheung, M. F., and Wong, C. S. (2011). Transformational leadership, leader support, and employee creativity. Leadersh. Organ. Dev. J. 32, 656-672. doi: $10.1108 / 01437731111169988$

Choi, B. K., and Moon, H. K. M. (2017). Subordinates' helping, voice, and supervisors' evaluation of job performance: the moderating effects of supervisor-attributed motives. Career Dev. Int. 22, 222-240. doi: 10.1108/CDI04-2016-0058

Cohen, A. (2016). Are they among us? A conceptual framework of the relationship between the dark triad personality and counterproductive work behaviors (CWBs). Hum. Resour. Manage. Rev. 26, 69-85. doi: 10.1016/j.hrmr.2015. 07.003

De Grood, J. A. (2009). In Sickness and in Health: A Test of Karasek's Job DemandControl-Support Model. Ann Arbor, MI: ProQuest.

de Jonge, J., and Peeters, M. C. (2009). Convergence of self-reports and coworker reports of counterproductive work behavior: a cross-sectional multi-source survey among health care workers. Int. J. Nurs. Stud. 46, 699-707. doi: 10.1016/ j.ijnurstu.2008.12.010

DeArmond, S., Matthews, R. A., and Bunk, J. (2014). Workload and procrastination: the roles of psychological detachment and fatigue. Int. J. Stress Manage. 21, 137-161. doi: 10.1037/a0034893

Demerouti, E., Bakker, A. B., Nachreiner, F., and Schaufeli, W. B. (2001). The job demands-resources model of burnout. J. Appl. Psychol. 86, 499-512. doi: 10.1037/0021-9010.86.3.499

Demerouti, E., Geurts, S. A., Bakker, A. B., and Euwema, M. (2004). The impact of shiftwork on work-home conflict, job attitudes and health. Ergonomics 47, 987-1002. doi: 10.1080/00140130410001670408

Eagle, B. W., Miles, E. W., and Icenogle, M. L. (1997). Interrole conflicts and the permeability of work and family domains: Are there gender differences? J. Vocat. Behav. 50, 168-184. doi: 10.1006/jvbe.1996.1569

Emslie, C., Hunt, K., and Macintyre, S. (2004). Gender, work-home conflict, and morbidity amongst white-collar bank employees in the United Kingdom. Int. J. Behav. Med. 11, 127-134. doi: 10.1207/s15327558ijbm1103_1

Fida, R., Paciello, M., Tramontano, C., Barbaranelli, C., and Farnese, M. L. (2015). "Yes, I Can": the protective role of personal self-efficacy in hindering counterproductive work behavior under stressful conditions. Anxiety Stress Coping 28, 479-499. doi: 10.1080/10615806.2014.969718

Flaxman, P. E., Ménard, J., Bond, F. W., and Kinman, G. (2012). Academics' experiences of a respite from work: effects of self-critical perfectionism and perseverative cognition on postrespite well-being. J. Appl. Psychol. 97, 854-865. doi: $10.1037 / \mathrm{a} 0028055$

Fritz, C., Sonnentag, S., Spector, P. E., and McInroe, J. A. (2010a). The weekend matters: relationships between stress recovery and affective experiences. J. Organ. Behav. 31, 1137-1162. doi: 10.1002/job.672

Fritz, C., Yankelevich, M., Zarubin, A., and Barger, P. (2010b). Happy, healthy, and productive: the role of detachment from work during non-work time. J. Appl. Psychol. 95, 977-983. doi: 10.1037/a0019462

Frone, M. R., Russell, M., and Cooper, M. L. (1992). Prevalence of work-family conflict: Are work and family boundaries asymmetrically permeable? J. Organ. Behav. 13, 723-729. doi: 10.1002/job.4030130708

Germeys, L., and De Gieter, S. (2016). Psychological detachment mediating the daily relationship between workload and marital satisfaction. Front. Psychol. 7:2036. doi: 10.3389/fpsyg.2016.02036

Gomez, J. T. R. (2014). The role of self-esteem and self-efficacy in moderating the effect of workplace stress on depression, anxiety and stress. Aust. J. Organ. Psychol. 7:e2. doi: 10.1017/orp.2014.2

Gramstad, T. O., Gjestad, R., and Haver, B. (2013). Personality traits predict job stress, depression and anxiety among junior physicians. BMC Med. Educ. 13, 150-158. doi: 10.1186/1472-6920-13-150

Greenidge, D., Devonish, D., and Alleyne, P. (2014). The relationship between ability-based emotional intelligence and contextual performance and counterproductive work behaviors: a test of the mediating effects of job satisfaction. Hum. Perform. 27, 225-242. doi: 10.1080/08959285.2014. 913591

Grieco, A. (1987). Scope and nature of sexual harassment in nursing. J. Sex Res. 23, 261-266. doi: 10.1080/00224498709551362

Hacker, W. (2003). Action regulation theory: a practical tool for the design of modern work processes? Eur. J. Work Organ. Psychol. 12, 105-130. doi: 10.1080/ 13594320344000075 
Hakanen, J. J., Bakker, A. B., and Demerouti, E. (2005). How dentists cope with their job demands and stay engaged: the moderating role of job resources. Eur. J. Oral Sci. 113, 479-487. doi: 10.1111/j.1600-0722.2005. 00250.x

Hakanen, J. J., Bakker, A. B., and Schaufeli, W. B. (2006). Burnout and work engagement among teachers. J. Sch. Psychol. 43, 495-513. doi: 10.1016/j.jsp. 2005.11.001

Halbesleben, J. R., and Bowler, W. M. (2007). Emotional exhaustion and job performance: the mediating role of motivation. J. Appl. Psychol. 92, 93-106. doi: $10.1037 / 0021-9010.92 .1 .93$

Hobfoll, S. E. (1989). Conservation of resources: a new attempt at conceptualizing stress. Am. Psychol. 44, 513-524. doi: 10.1037/0003-066X.44. 3.513

Husain, W., Gulzar, A., and Aqeel, M. (2016). The mediating role of depression, anxiety and stress between job strain and turnover intentions among male and female teachers. FWU J. Soc. Sci. 10, 48-57.

Hystad, S. W., Mearns, K. J., and Eid, J. (2014). Moral disengagement as a mechanism between perceptions of organisational injustice and deviant work behaviours. Saf. Sci. 68, 138-145. doi: 10.1016/j.ssci.2014.03.012

International Energy Agency (2000). Coal in the Energy Supply of China. Paris: International Energy Agency, 1-110. doi: 10.1177/014920631141 9663

Jensen, J. M., Patel, P. C., and Messersmith, J. G. (2013). High-performance work systems and job control: consequences for anxiety, role overload, and turnover intentions. J. Manage. 39, 1699-1724. doi: 10.1177/0149206311419663

Jourdain, G., and Chênevert, D. (2007). "Burnout among nursing staff and intention to leave the profession: validation of the job demands-resource model in hospitals in Québec," in Proceedings of the ASAC, Ottawa, ON.

Kanten, P., and Ulker, F. E. (2013). The effect of organizational climate on counterproductive behaviors: an empirical study on the employees of manufacturing enterprises. Macrotheme Rev. 2, 144-160. doi: 10.1111/joop. 12062

Kiazad, K., Seibert, S. E., and Kraimer, M. L. (2014). Psychological contract breach and employee innovation: a conservation of resources perspective. J. Occup. Organ. Psychol. 87, 535-556. doi: 10.1111/joop. 12062

Kinnunen, U., Feldt, T., Siltaloppi, M., and Sonnentag, S. (2011). Job demandsresources model in the context of recovery: testing recovery experiences as mediators. Eur. J. Work Organ. Psychol. 20, 805-832. doi: 10.1080/1359432X. 2010.524411

Kühnel, J., Sonnentag, S., and Westman, M. (2009). Does work engagement increase after a short respite? The role of job involvement as a double-edged sword. J. Occup. Organ. Psychol. 82, 575-594. doi: 10.1348/096317908X34 9362

Lazarus, R. S. (1991). "Psychological stress in the workplace," in Journal of Social Behavior and Personality: Handbook on Job Stress (Special Issue), Vol. 6, ed. P. L. Perrewe (San Rafael, CA: Select Press), 1-13.

Li, M., Wang, Z., Gao, J., and You, X. (2017). Proactive personality and job satisfaction: the mediating effects of self-efficacy and work engagement in teachers. Curr. Psychol. 36, 48-55. doi: 10.1007/s12144-015-9383-1

Li, S., Wang, Y., and Liu, Q. (2013). A model of unsafe behavior in coal mines based on game theory. Int. J. Min. Sci. Technol. 23, 99-103. doi: 10.1016/j.ijmst.2013. 01.015

Mathieu, J. E., and Farr, J. L. (1991). Further evidence for the discriminant validity of measures of organizational commitment, job involvement, and job satisfaction. J. Appl. Psychol. 76, 127-133. doi: 10.1037/0021-9010.76.1.1

McCarthy, J. M., Trougakos, J. P., and Cheng, B. H. (2016). Are anxious workers less productive workers? It depends on the quality of social exchange. Journal of Appl. Psychol. 101, 279-291. doi: 10.1037/apl0000044

Meijman, T. F., and Mulder, G. (1998). Psychological aspects of workload. Handb. Work Organ. Psychol. 2, 5-33.

Moreno-Jiménez, B., and Herrer, M. G. (2013). The effect of psychological detachment from work on well-being and life satisfaction: a longitudinal study. Rev. Psicol. Trabajoydelas Organ. 29, 145-151. doi: 10.5093/ $\operatorname{tr} 2013 \mathrm{a} 20$

Moreno-Jiménez, B., Rodríguezmuñoz, A., Sanzvergel, A. I., and Garrosa, E. (2012). Elucidating the role of recovery experiences in the job demandsresources model. Span. J. Psychol. 15, 659-669. doi: 10.5209/rev_SJOP.2012.v15. n2.38877
Muschalla, B., and Linden, M. (2014). Workplace phobia, workplace problems, and work ability among primary care patients with chronic mental disorders. J. Am. Board Fam. Med. 27, 486-494. doi: 10.3122/jabfm.2014.04. 130308

Nawawi, A., Khalil, M. A. K. M., and Mahzan, N. (2017). Banker's demographic characteristics and their perception on the risk of asset misappropriation: Malaysian evidence. e-Acad. J. 6, 228-239.

Netemeyer, R. G., Boles, J. S., and McMurrian, R. (1996). Development and validation of work-family conflict and family-work conflict scales. J. Appl. Psychol. 81, 400-410. doi: 10.1037/0021-9010.81.4.400

Neuman, J. H., and Baron, R. A. (2005). "Aggression in the workplace: a social psychological perspective," in Counterproductive Workplace Behavior: Investigations of Actors and Targets, eds S. Fox and P. E. Spector (Washington, DC: American Psychological Association), 13-40.

Ng, T. W., and Feldman, D. C. (2012). Employee voice behavior: a meta-analytic test of the conservation of resources framework. J. Organ. Behav. 33, 216-234. doi: $10.1002 /$ job.754

O'Neill, T. A., and Hastings, S. E. (2011). Explaining workplace deviance behavior with more than just the "Big Five". Pers. Individ. Dif. 50, 268-273. doi: 10.1016/ j.paid.2010.10.001

Parker, S. K. (1998). Enhancing role breadth self-efficacy: the roles of job enrichment and other organizational interventions. J. Appl. Psychol. 83, 835852. doi: $10.1037 / 0021-9010.83 .6 .835$

Penney, L. M., Hunter, E. M., and Perry, S. J. (2011). Personality and counterproductive work behaviour: using conservation of resources theory to narrow the profile of deviant employees. J. Occup. Organ. Psychol. 84, 58-77. doi: $10.1111 / j .2044-8325.2010 .02007 . x$

Pereira, D., and Elfering, A. (2014). Social stressors at work and sleep during weekends: the mediating role of psychological detachment. J. Occup. Health Psychol. 19, 85-95. doi: 10.1037/a0034928

Peters, R. H., and Clingan, M. R. (1989). Reducing coal miner absenteeism. Min. Sci. Technol. 9, 227-236. doi: 10.1016/S0167-9031(89)90347-2

Petitta, L., and Vecchione, M. (2011). Job burnout, absenteeism, and extra role behaviors. J. Workplace Behav. Health 26, 97-121. doi: 10.1080/15555240.2011. 573752

Podsakoff, P. M., MacKenzie, S. B., Lee, J. Y., and Podsakoff, N. P. (2003). Common method biases in behavioral research: a critical review of the literature and recommended remedies. J. Appl. Psychol. 88, 879-903. doi: 10.1037/0021-9010. 88.5.879

Podsakoff, P. M., MacKenzie, S. B., and Podsakoff, N. P. (2012). Sources of method bias in social science research and recommendations on how to control it. Annu. Rev. Psychol. 63, 539-569. doi: 10.1146/annurev-psych-120710-100452

Proenca, T., Torres, A., and Sampaio, A. S. (2017). Frontline employee empowerment and perceived customer satisfaction. Manag. Res. 15, 1-38. doi: 10.1108/MRJIAM-04-2016-0663

Prottas, D. J., Shea-Van Fossen, R. J., Cleaver, C. M., and Andreassi, J. K. (2017). Relationships among faculty perceptions of their tenure process and their commitment and engagement. J. Appl. Res. High. Educ. 9, 242-254. doi: 10. 1108/JARHE-08-2016-0054

Qing-gui, C., Kai, L., Ye-jiao, L., Qi-hua, S., and Jian, Z. (2012). Risk management and workers' safety behavior control in coal mine. Saf. Sci. 50, 909-913. doi: 10.1016/j.ssci.2011.08.005

Rijk, A. E., Blanc, P. M. L., Schaufeli, W. B., and Jonge, J. (1998). Active coping and need for control as moderators of the job demand-control model: effects on burnout. J. Occup. Organ. Psychol. 71, 1-18. doi: 10.1111/j.2044-8325.1998. tb00658.x

Robinson, S. L., and Bennett, R. J. (1997). "Workplace deviance: its definition, its manifestations, and its causes," in Research on Negotiation in Organizations, Vol. 6, eds R. J. Lewicki, R. J. Bies, and B. H. Sheppard (Philadelphia, PA: Elsevier Science), 3-27.

Robinson, S. L., and Bennett, R. J. (1995). A typology of deviant workplace behaviors: a multidimensional scaling study. Acad. Manag. J. 38, 555-572. doi: $10.2307 / 256693$

Robinson, S. L., and O'Leary-Kelly, A. M. (1998). Monkey see, monkey do: the influence of work groups on the antisocial behavior of employees. Acad. Manag. J. 41, 658-672. doi: 10.2307/256963

Rogers, W. M., and Schmitt, N. (2004). Parameter recovery and model fit using multidimensional composites: a comparison of four empirical 
parceling algorithms. Multivariate Behav. Res. 39, 379-412. doi: 10.1207/ S15327906MBR3903_1

Rothbard, N. P., Phillips, K. W., and Dumas, T. L. (2005). Managing multiple roles: work-family policies and individuals' desires for segmentation. Organ. Sci. 16, 243-258. doi: 10.1287 /orsc. 1050.0124

Rotundo, M., and Spector, P. E. (2010). "Counterproductive work behavior and withdrawal," in Handbook of Employee Selection, eds J. L. Farr and N. T. Tippins (New York, NY: Routledge), 489-511.

Safstrom, M., and Hartig, T. (2013). Psychological detachment in the relationship between job stressors and strain. Behav. Sci. 3, 418-433. doi: 10.3390/ bs3030418

Salami, S. O. (2010). Job stress and counterproductive work behaviour: negative affectivity as a moderator. Soc. Sci. 5, 486-492. doi: 10.3923/sscience.2010. 486.492

Salgado, J. F., Moscoso, S., and Berges, A. (2013). Conscientiousness, its facets, and the prediction of job performance ratings: evidence against the narrow measures. Int. J. Sel. Assess. 21, 74-84. doi: 10.1111/ijsa.12018

Salisbury, W. D., Chin, W. W., Gopal, A., and Newsted, P. R. (2002). Research report: better theory through measurement-developing a scale to capture consensus on appropriation. Inform. Syst. Res. 13, 91-103. doi: 10.1287/isre.13. 1.91 .93

Schaffer, B. S., and Riordan, C. M. (2003). A review of cross-cultural methodologies for organizational research: a best-practices approach. Organ. Res. Methods 6, 169-215. doi: 10.1177/1094428103251542

Schaufeli, W. B., Salanova, M., González-Romá, V., and Bakker, A. B. (2002). The measurement of engagement and burnout: a two sample confirmatory factor analytic approach. J. Happiness Stud. 3, 71-92. doi: 10.1023/A:10156309 30326

Schmidt, K. H., and Diestel, S. (2013). Job demands and personal resources in their relations to indicators of job strain among nurses for older people. J. Adv. Nurs. 69, 2185-2195. doi: 10.1111/jan.12082

Shulman, T. D. (2005). Biting the Hand that Feeds: The Employee Theft Epidemic. West Conshohocken, PA: Infinity Publishing

Skinner, N., and Brewer, N. (2002). The dynamics of threat and challenge appraisals prior to stressful achievement events. J. Pers. Soc. Psychol. 83, 678-692. doi: 10.1037/0022-3514.83.3.678

Sonnentag, S. (2011). "Recovery from fatigue: the role of psychological detachment," in Cognitive Fatigue: Multidisciplinary Perspectives on Current Research and Future Applications, 1st Edn, ed. P. L. Ackerman(Washington, DC: APA Sciences), 253-268.

Sonnentag, S. (2012). Psychological detachment from work during leisure time: the benefits of mentally disengaging from work. Curr. Dir. Psychol. Sci. 21, 114-118. doi: 10.1177/0963721411434979

Sonnentag, S., Arbeus, H., Mahn, C., and Fritz, C. (2014). Exhaustion and lack of psychological detachment from work during off-job time: moderator effects of time pressure and leisure experiences. J. Occup. Health Psychol. 19, 206-216. doi: $10.1037 / \mathrm{a} 0035760$

Sonnentag, S., Binnewies, C., and Mojza, E. J. (2008). "Did you have a nice evening?" A day-level study on recovery experiences, sleep, and affect. J. Appl. Psychol. 93, 674-684. doi: 10.1037/0021-9010.93.3.674

Sonnentag, S., and Fritz, C. (2007). The recovery experience questionnaire: development and validation of a measure for assessing recuperation and unwinding from work. J. Occup. Health Psychol. 12, 204-221. doi: 10.1037/ 1076-8998.12.3.204

Sonnentag, S., and Fritz, C. (2015). Recovery from job stress: the stressordetachment model as an integrative framework. J. Organ. Behav. 36, 72-103. doi: 10.1002/job. 1924

Sonnentag, S., Kuttler, I., and Fritz, C. (2010). Job stressors, emotional exhaustion, and need for recovery: a multi-source study on the benefits of psychological detachment. J. Vocat. Behav. 76, 355-365. doi: 10.1016/j.jvb.2009.06.005

Spector, P. E. (2005). Job stress, incivility, and counterproductive work behavior (CWB): the moderating role of negative affectivity. J. Organ. Behav. 26, 777-796. doi: $10.1002 /$ job.336

Spector, P. E. (2006). Method variance in organizational research: Truth or urban legend? Organ. Res. Methods 9, 221-232. doi: 10.1177/1094428105284955

Spector, P. E., and Fox, S. (2005a). "The stressor-emotion model of counterproductive work behavior," in Counterproductive Work Behavior:
Investigations of Actors and Targets, eds P. E. Spector and S. Fox (Washington, DC: American Psychological Association), 151-174.

Spector, P. E., and Fox, S. (2005b). "A model of counterproductive work behavior," in Counterproductive Workplace Behavior: Investigations of Actors and Targets, eds S. Fox and P. E. Spector (Washington, DC: American Psychological Association), 151-174. doi: 10.1037/10893-007

Spector, P. E., and Fox, S. (2002). An emotion-centered model of voluntary work behavior: some parallels between counterproductive work behavior and organizational citizenship behavior. Hum. Resour. Manag. Rev. 12, 269-292. doi: 10.1016/S1053-4822(02)00049-9

Srivastava, A. K. (1985). Moderating effect of $\mathrm{n}$ Ach. on role stress-job anxiety relationship. Psychol. Stud. 30, 102-106.

Starrenburg, A. H., Kraaier, K., Pedersen, S. S., van Hout, M., Scholten, M., and van der Palen, J. (2013). Association of psychiatric history and type D personality with symptoms of anxiety, depression, and health status prior to ICD implantation. Int. J. Behav. Med. 20, 425-433. doi: 10.1007/s12529-0129244-3

Sulea, C., Maricutoiu, L., Dumitru, C. Z., and Pitariu, H. D. (2015). Predicting counterproductive work behaviors: a meta-analysis of their relationship with individual and situational factors. Psihologia Resurselor Umane 8, $66-81$.

Swanson, V., Power, K. G., and Simpson, R. J. (1998). Occupational stress and family life: a comparison of male and female doctors. J. Occup. Organ. Psychol. 71, 237-260. doi: 10.1111/j.2044-8325.1998.tb0 0675.x

Taylor, A. (2007). Re: Gambling at Work "Costs Employers£; $300 M$ a Year". Available at: http://www.ft.com/cms/s/0/55009c0e-a43d-11db-bec40000779e2340.html\#axzz2mZJbxzmB [accessed January 4, 2007].

Trougakos, J. P., and Hideg, I. (2009). "Momentary work recovery: the role of within-day work breaks," in Current Perspectives on Job-Stress Recovery, eds S. Sonnentag, D. C. Ganster, and P. L. Perrewe (Bingley: Emerald Group Publishing), 37-84.

van der Doef, M., Maes, S., and Diekstra, R. (2000). An examination of the job demand-control-support model with various occupational strain indicators. Anxiety Stress Coping 13, 165-185. doi: 10.1080/1061580000824 8338

van Doorn, R. R., and Hülsheger, U. R. (2015). What makes employees resilient to job demands? The role of core self-evaluations in the relationship between job demands and strain reactions. Eur. J. Work Organ. Psychol. 24, 76-87. doi: 10.1080/1359432X.2013.858700

Vanderpool, C., and Way, S. A. (2013). Investigating work-family balance, job anxiety, and turnover intentions as predictors of health care and senior services customer contact employee voluntary turnover. Cornell Hosp. Q. 54, 149-160. doi: $10.1177 / 1938965513478682$

Vardi, Y., and Wiener, Y. (1996). Misbehavior in organizations: a motivational framework. Organ. Sci. 7, 151-165. doi: 10.1287/orsc.7. 2.151

Wei, J., Chen, H., and Qi, H. (2015). Who reports low safety commitment levels? An investigation based on Chinese coal miners. Saf. Sci. 80, 178-188. doi: 10.1016/j.ssci.2015.07.024

Xanthopoulou, D., Bakker, A. B., Dollard, M. F., Demerouti, E., Schaufeli, W. B., Taris, T. W., et al. (2007). When do job demands particularly predict burnout? The moderating role of job resources. J. Manag. Psychol. 22, 766-786. doi: $10.1108 / 02683940710837714$

Xue, B., and Ren, W. (2012). China's uncertain $\mathrm{CO}_{2}$ emissions. Nat. Clim. Change 2, 762. doi: 10.1038/nclimate1715

Yan, Z., Zhang, J., Yang, Z., and Li, S. (2011). Regional differences in the factors that influence china's energy-related carbon emissions, and potential mitigation strategies. Energy Policy 39, 7712-7718. doi: 10.1016/j.enpol.2011. 09.015

Zhang, H., Luo, X., Liao, Q., and Peng, L. (2015). Does it team climate matter? An empirical study of the impact of co-workers and the Confucian work ethic on deviance behavior. Inform. Manage. 52, 658-667. doi: 10.1016/j.im.2015. 05.006

Zhang, L., and Deng, Y. (2016). Guanxi with supervisor and counterproductive work behavior: the mediating role of job satisfaction. J. Bus. Ethics 134, 413-427. doi: 10.1007/s10551-014-2438-7 
Zhou, Z. E., Meier, L. L., and Spector, P. E. (2014). The role of personality and job stressors in predicting counterproductive work behavior: a three way interaction. Int. J. Sel. Assess. 22, 286-296. doi: 10.1111/ijsa.12077

Conflict of Interest Statement: The authors declare that the research was conducted in the absence of any commercial or financial relationships that could be construed as a potential conflict of interest.
Copyright (c) 2017 Chen, Li, Xia and He. This is an open-access article distributed under the terms of the Creative Commons Attribution License (CC BY). The use, distribution or reproduction in other forums is permitted, provided the original author(s) or licensor are credited and that the original publication in this journal is cited, in accordance with accepted academic practice. No use, distribution or reproduction is permitted which does not comply with these terms. 